\title{
A Locally Isolated Entomopathogenic Fungus to Control Tea Red Spider Mites (Oligonychus coffeae Acarina -Tetranychidae)
}

\author{
P.G.D.S. Amarasena, K.M. Mohotti ${ }^{1 *}$ and D. Ahangama ${ }^{2}$ \\ Postgraduate Institute of Agriculture \\ University of Peradeniya \\ Peradeniya
}

\begin{abstract}
Mites are considered as seasonal pests in tea. They cause significant damage to the crop during dry weather. However, the restrictions imposed by tea importers on pesticide residues in made tea pose an immediate need to identify alternative control methods for Propargite (a synthetic acaricide) and sulphur which are the current recommendations. The alternative methods should be effective, biological, safe and acceptable to the importers. Previous attempts have been made to screen predatory mites and entomopathogenic fungi against tea mites; however, local sources have not yet been investigated. The present study was conducted to explore the possibilities in biological control methods with specific objectives of isolating and preliminary screening of local entomopathogenic fungi against tea mites under laboratory conditions. In this study, naturally occurring fungal species from six different tea ecosystems reducing populations of tea red spider mites (Oligonychus coffeae) were isolated. The laboratory experiments conducted on mite-infested excised-leaves confirmed that the unidentified fungus coded as HF1 was significantly $(p<0.05)$ effective in reducing mite populations. The Fungal isolate gave $65 \%$ mortality while the highest mortality of $75 \%$ was achieved by the TRI recommended acaricide, Propargite. Comparatively, $\underline{H}$. thompsonii and neem seed extract exhibited lower mortality. This is the first record of isolation of entomopathogenic fungi from tea mites in Sri Lanka. The preliminary results foresee the potential of harnessing local entomopathogenic fungi in managing tea mites as an environmentally safe and effective treatment.
\end{abstract}

Key words: Entomopathogenic fungi, Hirsutella thompsonii. Red spider mites.

\section{INTRODUCTION}

People all over the world consume tea as a health drink and hence, it is essential to maintain its purity and safety by avoiding deterioration of the product due to the use of hazardous chemicals. Furthermore, there is an emerging demand for tea produced without the use of pesticides. In addition, the serious groundwater pollution which has occurred as a result of excessive use of fertilizer and pesticides has become an issue in tea-growing areas. As a solution to these problems, some groups of tea growers have started producing tea using no chemicals at all, or with minimum usage of chemicals. However, there is a demand for ecologically sound management methods against pests of tea for use in outbreak situations.

To whom correspondence should be addressed: mohottik@yahoo.com

Entomology and Nematology Division, Tea Research Institute of Sri Lanka, Talawakele, Sri Lanka

Department of Agricultural Biology, Faculty of Agriculture, University of Peradeniya, Peradeniya, Sri Lanka 
Most of the species of microscopic mites occupy the lower surface of leaves, however, a few prefer to dwell on the upper surface. They damage the green tissues of leaves and reduce the photosynthetic surface, resulting in yield reduction. The infestation leads to discoloration of leaves. Feeding by mites has a long lasting effect on the tea bushes when the damage is severe enough to cause either defoliation or set back of growth (Cranham, 1966, Vitarana, 1990, Senaratna and Mohotti, 2008).

The mites are phytophagous, with outbreaks occurring during dry weather (May to September in North East monsoon zone and January to April in the South West monsoon zone). The red spider mite (Oligonychus coffeae Acarina-Tetranychidae), the scarlet mite (Brevipalpus californicus Acarina -Tenuipalpidae), the purple mite (Calacarus carma Acarina Eriophyidae), yellow mite (Hemltarsonemus latus Acarina -Tarsonemidae) and pink mite (Acaphylla theae K. Acarina - Eriophyidae) are the five mite pests recorded in tea in Sri Lanka (Vitarana, 2000).

The present recommendations for controlling tea mite include application of Propargite (a synthetic acaricide) for stages of the crop and sulphur for non-plucking fields due to its taint. Since longer Pre Harvest Intervals (PHIs) and stringent Maximum Residue Limits (MRL) are stipulated by importing countries, the need for alternative means of mite control is of paramount importance (FAO, 2010). Biological control entails the utilization of natural enemies, predators, parasitoids and pathogens for the management of pests. Fungi are the predominant pathogens found in insect populations, and are unique in their ability to infect their hosts through the external cuticle. Thus, they are capable of infecting both soft- and hard-bodied insects (ICARDA, 2005).

The studies conducted by the Coconut Research Institute of Sri Lanka revealed that the native predatory mite Neoseilulas baraki (Acari - Phytoseiidae) is a prospective biological control agent of the coconut mite (Mayooran et al., 2005). Furthermore, Fernando, et al., (2007) showed that entomopathogenic fungus Hirsutella thompsonii obtained from the coconut mite, Aceria guerreronis, is effective as a biopesticide.

The Tea Research Institute (TRI) of Sri Lanka has made several attempts to use biological control agents on mites. Nagahaulla and Danthanarayana (1999) identified predatory mites as biocontrol agents. Laboratory studies showed that the entomopathogenic fungi, Entomopthora sp. and Verticillium sp., could infect Oligonychus coffeae (Vitarana, 2000).

In the absence of any information on mycological pathogens with respect to tea mite control, the present study was conducted to explore possibilities of biological control with specific objectives of isolation and preliminary screening of local entomopathogenic fungi against tea mites under laboratory conditions.

\section{MATERIALS AND METHODS}

\section{Isolation of entomopathogenic fungi}

The mite prone areas were selected using the TRI records for collection of mites. Special attention was given to select the sampling sites of mite affected tea fields without or with least pesticide applications in view of capturing more organisms responsible in natural management of mites (Table 1). 
The mite infested leaves were randomly sampled from the selected locations. The samples were brought to the laboratory under wet conditions. The mites on the leaf surfaces were carefully removed under sterile conditions for culturing purposes.

Table 1. Sampling sites and isolate codes

\begin{tabular}{lcll}
\hline Location & $\begin{array}{c}\text { Agro Ecological } \\
\text { Region }\end{array}$ & \multicolumn{1}{c}{ Description } & $\begin{array}{c}\text { Isolate } \\
\text { Code }\end{array}$ \\
\hline $\begin{array}{l}\text { Needwood Estate, Haputale } \\
\text { Idulgastenna Bio Tea Project, }\end{array}$ & IU3a & Organically managed system & NW1 \\
Haldummulla & IU3a & Organically managed system & ST1 \\
$\begin{array}{l}\text { St. Coombs Estate, Talawakele } \\
\text { Mattakele Estate, Talawakele }\end{array}$ & WU2a & Organically managed system & SC1 \\
$\begin{array}{l}\text { High Forest Estate, Ragala } \\
\text { Summerset Estate, Talawakele }\end{array}$ & IU2 & Conventionally managed system & MK1 \\
\hline
\end{tabular}

The mites were surface sterilized under aseptic conditions and placed on Potato Dextrose Agar (PDA) which had been sterilized for $20 \mathrm{~min}$ at $121^{\circ} \mathrm{C}$ at $15 \mathrm{psi}$. The cultures were incubated at $25^{\circ} \mathrm{C}$ temperature and observed for fungal growth. The fungal mycelia observed on mite body and the surrounding media were transferred to sterilized PDA plates separately. Pure lines of the isolated fungus were grown on PDA which had been sterilized for $20 \mathrm{~min}$ at $121^{\circ} \mathrm{C}$ at 15 psi and culture plates were incubated at $25^{\circ} \mathrm{C}$ for 3 weeks and stored at $4^{0} \mathrm{C}$.

Among the naturally occurring fungal species from the six different tea ecosystems isolated (Table 1), the isolate HF 1 was selected for laboratory bioassays since it showed best performance in terms of mycelial growth in mass culturing.

\section{Laboratory bioassays}

To prepare fungal inocula, $10 \mathrm{~mL}$ of sterilized distilled water was added to 3 week old fungal culture and shaken for 2-3 min and the suspension was collected into sterilized dark coloured glass bottles under aseptic conditions. The bottles were stored at $4{ }^{\circ} \mathrm{C}$ until use for bioassays. The bioassays I, II, III and IV of which the treatments are given in Tables 2 and 3 were carried out at the Central Biological Control Laboratory of the TRI, Talawakelle, Sri Lanka.

Table 2. Treatments used in bioassays I and II

\begin{tabular}{ll}
\hline Treatment & Description \\
\hline Fungal Isolate (HF1) & 3 weeks old culture \\
Propargite & Recommended acaricide, Recommended dose (1 L \\
& in 600 L of water basis) as positive control \\
Distilled Water & As the negative control \\
Untreated Control & To detect natural mortality \\
\hline
\end{tabular}

All the bioassays were carried out to determine the pathogenicity of fungal isolate (HF1). Leaves were selected from the cultivar TRI 2025. To keep condition of leaves unchanged, moisturized cotton wool was placed at the end of stalk of leaves. Ten adult mites per replicate were introduced to the surface of the leaves. The culture plates were washed with same volume of distilled water and fungal spores were collected. Spraying was carried out and the leaves were placed under room temperature. The number of dead mites was 
recorded. $24 \mathrm{~h}$ after the treatment. Each treatment contained three replicates and the mean $\%$ mortality of mites was calculated.

Table 3. Treatments used in bioassays III and IV

\begin{tabular}{ll}
\hline Treatment & Description \\
\hline Fungal Isolate (HF1) & 3 weeks old culture \\
Hirsutella thompsonii & $\begin{array}{l}\text { Culture obtained from Coconut Research Institute which was used } \\
\text { as a biocontrol agent for coconut mite control (Fernando, 2007) }\end{array}$ \\
Neem Seed Extract & $\begin{array}{l}\text { 1\% Azadirachtin, commercial product, 1 g in 10 L of water basis } \\
\text { Propargite }\end{array}$ \\
& $\begin{array}{l}\text { Recommended acaricide, recommended dose (1 Lin 600 L of } \\
\text { water basis) }\end{array}$ \\
Distilled Water & As the negative control \\
Untreated Control & To detect natural mortality \\
\hline
\end{tabular}

In order to re isolate the fungi from mite cadavers, the mites were dipped in $70 \%$ ethanol to sterilize the surface of cadavers and dipped in sterilize distilled water three times to wash off excess ethanol. Surface sterilized cadavers were cultured on PDA plates. The plates were incubated at $25^{\circ} \mathrm{C}$ for one week and colony characters were observed. Data were analyzed using Statistical Analyze System (SAS) software package. Duncan's Multiple Range Test (DMRT) was used to examine whether the differences of mean values of each dependent variable were significant.

\section{Fungal culture}

\section{RESULTS AND DISCUSSION}

A white coloured fungal mycelium was observed on the PDA medium 5 days after culturing. The hyphae started growing very rapidly and the globose shaped spore like structures were observed two weeks after incubation (Plate 1). The mycelia became greenish in colour after four weeks time and produced green pigment into the medium. Identification of the fungus is in progress at the Indian Institute of Horticulture Research (IIHR), Bangalore, India.

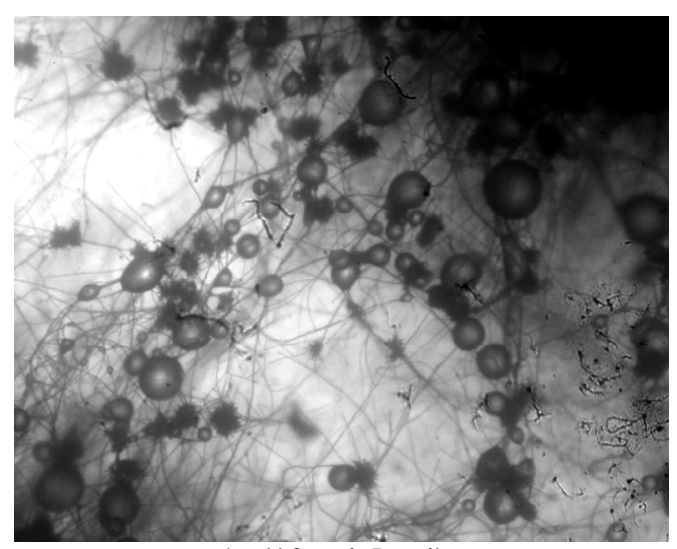

A: $(10 \times 4.5 \times 4)$

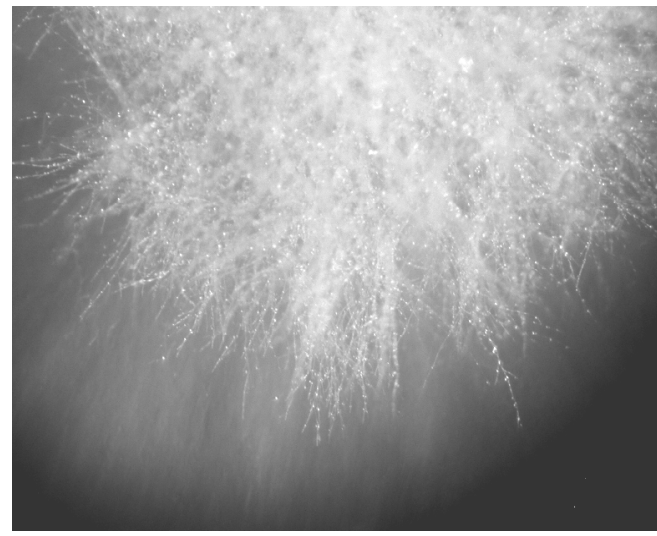

B: $(10 \times 1 \times 2)$

Plate 1. Appearance of the 3 weeks old fungal mycelium of HF 1 grown on PDA medium (A: magnified picture showing globose shaped spore like structures, B: fungal mycelium) 
Results of the bioassay I showed that the TRI recommended acaricide, Propargite gave the highest \% mortality (66\%) of red spider mites $24 \mathrm{~h}$ after application (Fig. 1). The fungal isolate (HF1) showed a significantly higher $(\mathrm{p}=0.05)$ mortality of $62 \%$ over untreated control.

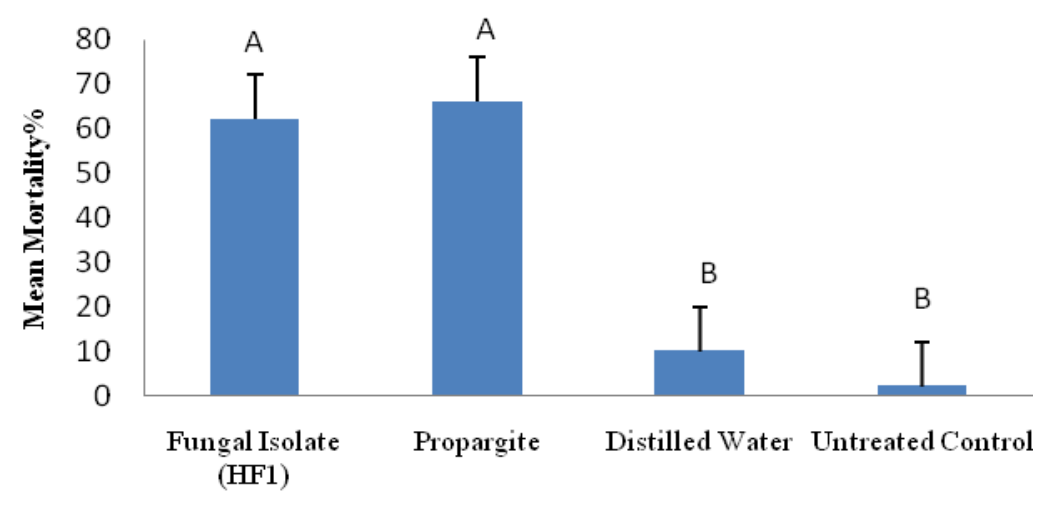

Treatments

Fig. 1. Mean \% mortality of Red spider mites $24 \mathrm{~h}$ after treatment (Bioassay I) Means with different letters are significantly different at $p=0.05$.

A similar trend was observed in bioassay II as shown in Fig. 2. Both the recommended acaricide Propargite and the fungal isolate (HF1) treated red spider mites showed higher mortality of red spider mites $24 \mathrm{~h}$ after treatment. Interestingly, the \% mortality shown by HFI and the commercial chemical product Propargite is not significantly different with each other.

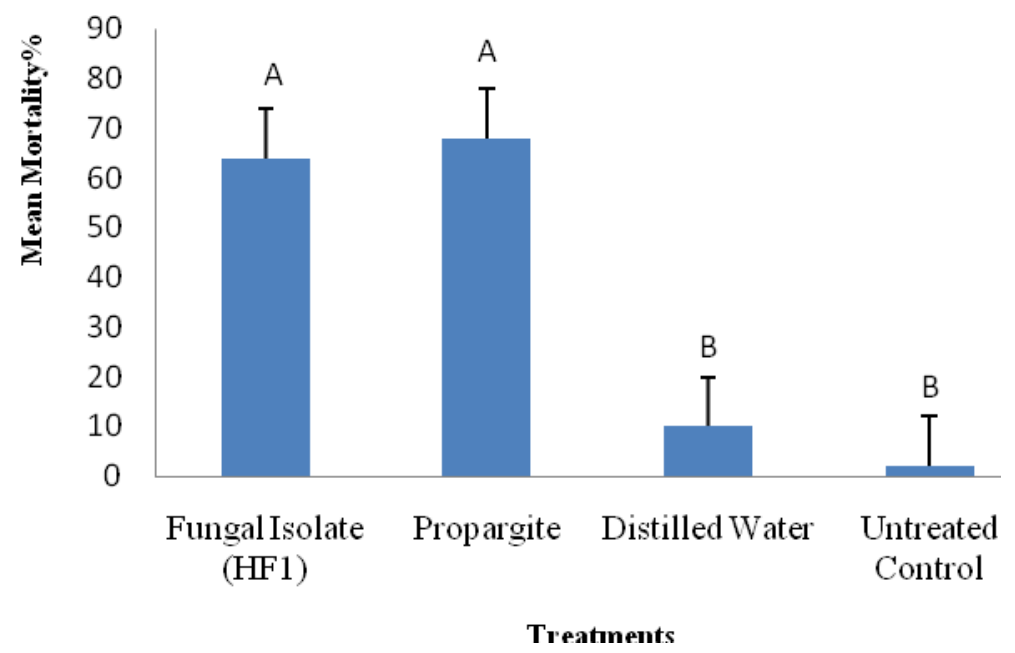

Fig. 2. Mean \% mortality of Red spider mites $24 \mathrm{~h}$ after treatment (Bioassay II) Means with different letters are significantly different at $\mathbf{p}=\mathbf{0 . 0 5}$. 
In bioassay III, there were two additional treatments (i.e. Hirsutella thompsonii and Neem seed extract). In this experiment too, Propargite and Fungal isolate (HF1) gave the highest mortality of tea mites (Fig. 3). Hirsutella thompsonii and Neem seed extract also resulted in comparatively higher mortality although not as high as the \% mortality given by Propargite and Fungal isolate (HF1).

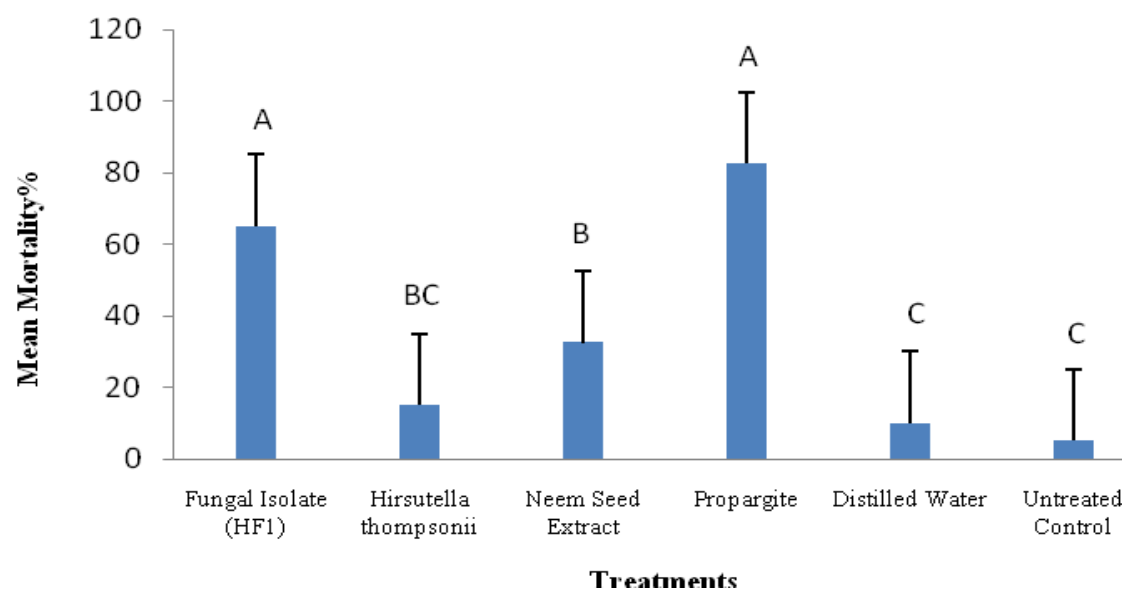

Fig. 3. Mean \% mortality of Red spider mites $24 \mathrm{~h}$ after treatment (Bioassay III) Means with different letters are significantly different at $\mathbf{p}=0.05$.

Similar results were obtained in the repetition trial viz. bioassay III (Fig. 4) which confirmed the potential of reducing the density of mite population on tea leaves by biological control agents.

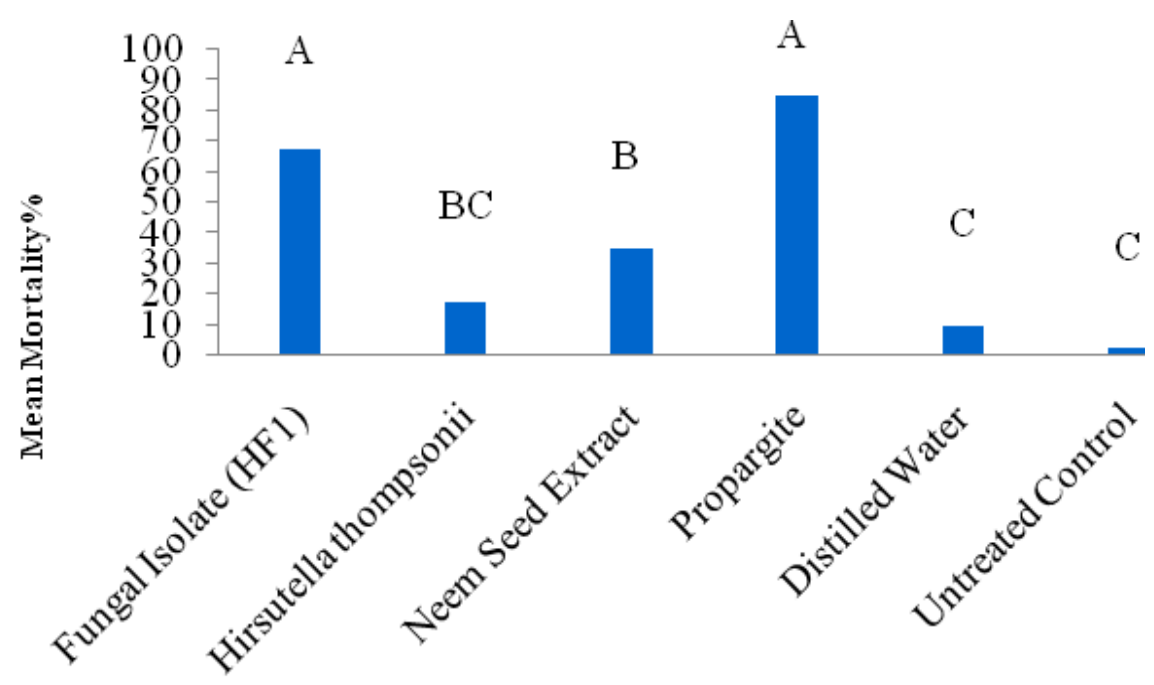

Treatments

Fig. 4. Mean \%Mortality of Red spider mites $24 \mathrm{~h}$ after treatment (Bioassay IV) Means with different letters are significantly different at $\mathbf{p}=\mathbf{0 . 0 5}$. 
In general, the Fungal isolate (HF1) gave $65 \%$ mortality of the red spider mites. The highest mortality of $75 \%$ was given by the TRI recommended acaricide, Propargite. Hirsutella thompsonii and Neem seed extract resulted in $14 \%$ and $31 \%$ mortality, respectively.

Table 3. Summary of the results of bioassays I-IV

\begin{tabular}{|c|c|c|c|c|c|c|}
\hline \multirow{2}{*}{ Treatment } & \multicolumn{4}{|c|}{ Mean \% mortality } & \multirow{2}{*}{ Mean } & \multirow{2}{*}{ SD } \\
\hline & I & II & III & IV & & \\
\hline Fungal isolate (HF1) & 62 & 64 & 65 & 67.5 & 64.6 & 30.0 \\
\hline Hirsutella thompsonii & & & 15 & 17.5 & 16.3 & 29.0 \\
\hline Neem seed extract & & & 32.5 & 35 & 33.8 & 32.7 \\
\hline Propargite & 66 & 68 & 82.5 & 85 & 75.4 & 40.0 \\
\hline Distilled water & 10 & 10 & 10 & 10 & 10.0 & 5.0 \\
\hline Untreated control & 2 & 2 & 5 & 2.5 & 2.9 & \\
\hline
\end{tabular}

\section{Isolation of fungi from mite cadavers}

The dead mites from all bioassays were placed on PDA plates for further observations. Fungal re isolation could be achieved only from the mites treated with fungal isolate (HFI). This showed the persistence of the fungi on dead mites which could possibly be available for infection of mites in next generations which is vital for the sustainability of biological control.

\section{CONCLUSIONS}

Only a few records were available on local entomopathogenic fungi in tea in Sri Lanka and other tea growing countries. Therefore, this study reported the first record of isolation of entomopathogenic fungi from tea mites. In this study, a naturally occurring fungal species which has the ability to reduce populations of the Tea Red Spider Mites (Oligonychus coffeae) were isolated from High Forest estate, Ragala. The laboratory experiments conducted on mite-infested excised-leaves confirmed that HF1 was effective in reducing mite populations. The fungal isolate gave $65 \%$ mortality while highest mortality of $75 \%$ was achieved by the TRI recommended acaricide, Propargite; comparatively, Hirsutella thompsonii and Neem seed extract exhibited lower mortality percentage than HFI. The results of the study confirmed that the locally isolated fungus is as effective or even better than the synthetic chemical in terms of reducing mite populations and can be used as an alternative in controlling mites in organic tea cultivations. The identification of the fungal isolate and the mode of action of the fungus against tea mites, are yet to be confirmed.

\section{ACKNOWLEDGEMENTS}

The financial support provided by TRI of Sri Lanka under Project A 32.3 to conduct the study is gratefully acknowledged. A special thank goes to Dr. L.C. P. Fernando, Crop Protection Division, Coconut Research Institute of Sri Lanka for providing Hirsutella thompsonii cultures. 


\section{REFERENCES}

Cranham, J. E. (1966). Insect and mite pest of tea in Ceylon and their control. Monographs on Tea Production in Ceylon, Tea Research Institute of Ceylon. No. 6, pp. 122.

Fernando, L. C. P., Manoj, P., Hapuarachchi D. C. L. and Edgington, S. (2007). Evaluation of four isolates of Hirsutella thompsonii against coconut mite (Aceria guerreronis) in Sri Lanka .Crop Protection, 26, 1062-1066.

http:// www.fao.org/es/esc/common/ecg/296/en/03_6_mrls.doc Maximum residue levels

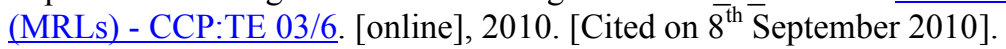

http:// www.icarda.cgiar.org/APRP/Datepalm/Topics/Pest/Pestright.htm. Integrated Pest Management [online], 2005. [Cited on $2^{\text {nd }}$ May 2009].

Mayooran, P., Fernando, L. C. P. and Fernandopulle, M. N. D. (2005). Increase rate of the predatory mite Neoseiulas baraki of coconut mite. Proceedings of 5th Agricultural Research Symposium Part II. Faculty of Agriculture \& Plantation Management, Wayamba University of Sri Lanka. 124-125.

Nagahaulla, S. M. and Danthanarayana, W. (1999). Natural enemies of mite pests of tea and biological control aspects. Tea Bulletin, 16 (1\&2), 69-83.

Senaratna K. A. D. W. and Mohotti, K. M. (2008). Management of insect and mites pests. In: Hand Book on Tea. Ed; Zoysa, A. K. N. Tea Research Institute of Sri Lanka. 231-240.

Vitarana, S. I. (1990). Mite outbreaks timely identification for effective implementation of acaricide control measure in tea lands. Tea Bulletin, 10 (2), 9-15.

Vitarana, S. I. (2000). 75 years of Research in Entomology, Acarology and Nematology, In: Twentieth Century Tea Research in Sri Lanka. Ed; Modder, W. W. D. Tea Research Institute of Sri Lanka, Talawakelle, Sri Lanka. Pp.111-160. 